\title{
Mean Platelet Component Measurement
}

National Cancer Institute

\section{Source}

National Cancer Institute. Mean Platelet Component Measurement. NCI Thesaurus.

Code C96686.

The determination of the amount of mean platelet component present in a sample. 